\title{
Islet cell autoantibodies
}

National Diabetes Information Clearinghouse (NDIC)

\section{Definitions}

Protein

Defined by National Diabetes Information Clearinghouse (NDIC)

Type 1 diabetes

Defined by National Diabetes Information Clearinghouse (NDIC)

Immune system

Defined by National Diabetes Information Clearinghouse (NDIC)

Beta cell

Defined by National Diabetes Information Clearinghouse (NDIC)

Pancreas

Defined by National Diabetes Information Clearinghouse (NDIC)

\section{Source}

National Diabetes Information Clearinghouse (U.S.). (2009). The diabetes dictionary. [Bethesda, Md.]: U.S. Dept. of Health and Human Services, National Institutes of Health, National Institute of Diabetes and Digestive and Kidney Diseases, National Diabetes Information Clearinghouse.

Proteins found in the blood of people newly diagnosed with type 1 diabetes. They are also found in people who may be developing type 1 diabetes. The presence of ICAs indicates the body's immune system has been damaging beta cells in the pancreas. The antibodies that are routinely tested for include IAA, IA-2A, ICA512, and GAD65 (also called GAD or GADA). 